\title{
Further Developments on the T-Transmuted $X$ Family of Distributions II
}

\author{
Clement Boateng Ampadu ${ }^{1}$, Suleman Nasiru ${ }^{2}$ and Girish Babu ${ }^{3}$ \\ ${ }^{1} 31$ Carrolton Road, Boston, MA 02132-6303, USA \\ ${ }^{2}$ Pan African University, Institute for Basic Sciences, Nairobi, Kenya \\ ${ }^{3}$ Department of Statistics, Government Arts and Science College, India
}

Submission: April 12, 2018; Published: September 14, 2018

*Corresponding author: Clement Boateng Ampadu, 131 Carrolton Road, Boston, MA 02132-6303, USA; Email: DrAmpadu@hotmail.com

Abstract

[1].

We review the exponentiated generalized (EG) T-X family of distributions and propose some further developments of this class of distributions

Keywords: T-X(W) family of distributions; Transmuted family of distributions; Exponentiated

Abbreviations: EG: exponentiated generalized; QRTM: Quadratic Rank Transmutation Map;

\section{Introduction}

\section{Transmuted family of distributions}

According to the quadratic rank transmutation map (QRTM) approach in Shaw W, et al. [2], the CDF of the transmuted family of distributions is given by

$$
F(x):=(1+\lambda) G(x)-\lambda G(x)^{2}
$$

Where, $-1 \leq \lambda \leq 1$ and $G(x)$ is the CDF of the base distribution. When $\lambda=0$ we get the CDF of the base distribution

Remark 1.1. The PDF of the transmuted family of distributions is obtained by differentiating

the CDF above.

A plethora of results discussing properties and applications of this class of distributions have appeared in the literature, and for examples see Faton Merovci, et al. [3] and Muhammad Shuaib Khan, et al [4].

\section{$\mathrm{T}-\mathrm{X}(\mathrm{W})$ family of distributions}

This family of distributions is a generalization of the betagenerated family of distributions first proposed by Eugene et al. [5]. In particular, let $r(t)$ be the PDF of the random variable $T \in[a, b], \quad-\infty \leq a<b \leq \infty$, and let $W(F(x))$ be a monotonic and absolutely continuous function of the CDF $F(x)$ of any random variable $X$. The CDF of a new family of distributions defined by Alzaatreh et al. [6] is given by

$$
G(x)=\int_{a}^{W(F(x))} r(t) d t=R\{W(F(x))\}
$$

Where $R(\cdot)$ is the CDF of the random variable T and $a \geq 0$

Remark 1.2. The PDF of the $T-X(W)$ family of distributions is obtained by differentiating the CDF above

Remark 1.3. When we set $W(F(x)):=-\ln (1-F(x))$, then we use the term "T-X Family of Distributions" to describe all sub-classes of the $T-X(W)$ family of distributions induced by the weight function $W(x)=-\ln (1-x)$. A description of different weight functions that are appropriate given the support of the random variable $\mathrm{T}$ is discussed in Alzaatreh A, et al. [6]

A plethora of results studying properties and application of the $T-X(W)$ family of distributions have appeared in the literature, and the research papers, assuming open access, can be easily obtained on the web via common search engines, like Google, etc.

\section{T-Transmuted $\mathbf{X}$ family of distributions}

This class of distributions appeared in Jayakumar K, et al. [7]. In particular the CDF admits the following integral representation for $a \geq 0$

$$
J(x)=\int_{a}^{-\ln (1-F(x))} r(t) d t
$$

Where $r(t)$ is the PDF of the random variable $T$ and $F(x)$ is the transmuted CDF of the random variable $X$, that is,

$$
F(x):=(1+\lambda) G(x)-\lambda G(x)^{2}
$$

Where $-1 \leq \lambda \leq 1$ and $G(x)$ is the CDF of the base distribution.

Remark 1.4. The PDF of the T-Transmuted $X$ family of distributions is obtained by differentiating the CDF above. 


\section{The exponentiated generalized (EG) T-X family of} distributions

This class of distributions appeared in Suleman Nasiru, et al. [1]. In particular the CDF admits the following integral representation

$$
G(x)=\int_{0}^{-\log \left[1-\left(1-\bar{F}(x)^{d}\right)^{c}\right]} r(t) d t
$$

Where, $c, d>0$ and $\bar{F}(x)=1-F(x)$

Remark 1.5. Note that if we set $L(x):=\left(1-\bar{F}(x)^{d}\right)^{c}$, where $c, d>0$ and $\bar{F}(x)=1-F(x)$, then ${ }^{L(x)}$ gives the CDF of the exponentiated generalized class of distributions [8]

\section{Further developments}

In this section, inspired by quantile generated probability distributions and the T transmuted X family of distributions $[6,9]$, we propose some new extensions of the exponentiated generalized (EG) T-X family of distributions. We give the CDF of these new class of distributions, only in integral form. However, the CDF and PDF can be obtained explicitly by applying Theorem 2.2 and Theorem 2.3 , respectively.

\section{The $q_{T}-X$ family of distributions}

Definition 2.1. Let $V$ be any function such that the following holds:

a) $\quad F(x) \in[V(a), V(b)]$

b) $\quad F(x)$ is differentiable and strictly increasing

c) $\quad \lim _{x \rightarrow-\infty} F(x)=V(a)$ and $\lim _{x \rightarrow-\infty} F(x)=V(b)$

then the CDF of the $q_{T}-X$ family induced by $V$ is given by

$$
K(x)=\int_{a}^{V(F(x))} \frac{1}{r(Q(t))} d t
$$

Where $\frac{1}{r(Q(t))}$ is the quantile density function of random variable $T \in[a, b]$, for $-\infty \leq a<b \leq \infty$, and $F(x)$ is the CDF of any random variable $X$.

Theorem 2.2. The CDF of the $q_{T}-X$ family induced by $V$ is given by $K(x)=Q[V(F(x))]$

Proof. Follows from the previous definition and noting that $Q^{\prime}=\frac{1}{r o Q}$

Theorem 2.3. The PDF of the $q_{T}-X$ family induced by $V$ is given by

$$
k(x)=\frac{f(x)}{r[Q(V(F(x)))]} V^{\prime}[F(x)]
$$

Proof. $k=K^{\prime}, Q^{\prime}=\frac{1}{r o Q}, F^{\prime}=f$ and $K$ is given by Theorem 2.2

Remark 2.4. When the support of $T$ is $[a, \infty)$, where $a \geq 0$, we can take $V$ as follows

$$
\begin{array}{cl}
\text { I. } & V(x)=1-e^{-x} \\
\text { II. } & V(x)=\frac{x}{1+x} \\
\text { III. } & V(x)=\left[1-e^{-x}\right]^{\frac{1}{\alpha}} \text {, where } \alpha>0 \\
\text { IV. } & V(x)=\left[\frac{x}{1+x}\right]^{\frac{1}{\alpha}}, \text { where } \alpha>0
\end{array}
$$

Remark 2.5. When the support of T is $(-\infty, \infty)$, we can take $V$ as follows

$$
\begin{aligned}
\text { i. } & V(x)=1-e^{-a x} \\
\text { ii. } & V(x)=\frac{e^{x}}{1+e^{x}} \\
\text { iii. } & V(x)=\left[\frac{e^{-x}}{1+e^{x}}\right]^{\frac{1}{x}} \text {, where } \alpha>0 \\
\text { iv. } & V(x)=\left[\frac{e^{x}}{1+e^{x}}\right]^{\frac{1}{a}} \text {, where } \alpha>0
\end{aligned}
$$

Definition 2.6. A random variable $W$ (say) is said to be transmuted exponentiated generalized

distributed if the CDF is given by

$$
(1+\lambda) L(x)-\lambda L(x)^{2}
$$

Where, $\quad-1 \leq \lambda \leq 1, \quad L(x):=\left(1-\bar{F}(x)^{d}\right)^{c}, \quad c, \quad d>0, \quad \bar{F}(x)=1-F(x)$, and $F(x)$ is a base distribution.

\section{Some EG $q_{T}$ transmuted $X$ family of distributions}

In what follows we assume the random variable $T$ has PDF $r(t)$ and quantile function $Q(t)$. We also assume the random variable $X$ has transmuted $\mathrm{CDF}$

$$
(1+\lambda) L(x)-\lambda L(x)^{2}
$$

Where $-1 \leq \lambda \leq 1, L(x):=\left(1-\bar{F}(x)^{d}\right)^{c}, \quad C, \quad d>0, \bar{F}(x)=1-F(x)$, and $F(x)$ is a base distribution.

\section{Families of EG $q_{T}$-transmuted $X$ distributions of type I}

The CDF has the following integral representation for $\alpha>0$ and $a \geq 0$

$$
K(x)=\int_{a}^{\left[1-e^{-\left\{(1+\lambda) L(x)^{2}\right\}}\right]^{\frac{1}{\alpha}}} \frac{1}{r(Q(t))} d t
$$

Families of EG $q_{T}$ transmuted $X$ distributions of type II

The CDF has the following integral representation for $\alpha>0$ and $a \geq 0$

$$
K(x)=\int_{a}^{\left[\frac{\left\{(1+\lambda) L(x)-\lambda L(x)^{2}\right\}}{1+\left\{(1+\lambda) L(x)-\lambda L(x)^{2}\right\}}\right]^{\frac{1}{\alpha}}} \frac{1}{r(Q(t))} d t
$$

\section{Families of EG $q_{T}$ transmuted $X$ distributions of Type III}

The CDF has the following integral representation for $\alpha>0$

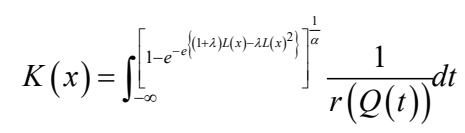

\section{Families of EG $q_{T}$-transmuted $X$ distributions of type IV}

The CDF has the following integral representation for $\alpha>0$

$$
K(x)=\int_{-\infty}^{\left[\frac{e\left\{(1+\lambda) L(x)-\lambda L(x)^{2}\right\}}{1+e\left\{(1+\lambda) L(x)-\lambda L(x)^{2}\right\}}\right]^{\frac{1}{\alpha}}} \frac{1}{r(Q(t))} d t
$$

\section{Concluding Remarks}

Our hope is that researchers will find these class of distributions practically significant in modeling biological data, 
health data, etc. We hope the researchers will further develop the properties and applications of these new class of distributions.

\section{References}

1. Suleman Nasiru, Peter NM, Oscar Ngesa (2017) Exponentiated Generalized Transformed- Transformer Family of Distributions. Journal of Statistical and Econometric Methods 6(4): 1-17.

2. Shaw W, Buckley I (2007) The alchemy of probability distributions: beyond Gram-Charlier expansions, and a skew-kurtotic-normal distribution from a rank transmutation map. Research report.

3. Faton Merovci, Ibrahim Elbatal (2014) Transmuted Weibull-geometric distribution and its applications. Scientia Magna 10(1): 68-82.

4. Muhammad Shuaib Khan, Robert King, Irene Lena Hudson (2016) Transmuted Gompertz Distribution: Properties And Estimation. Pak J Statist 32(3): 161-182.
5. Eugene N, Lee C, Famoye F (2002) The beta-normal distribution and its applications. Communications in Statistics-Theory and Methods 31(4): 497-512.

6. Alzaatreh A, Lee C, Famoye F (2013) A new method for generating families of continuous distributions. Metron 71(1): 63-79.

7. Jayakumar K, Girish Babu M (2017) T-Transmuted X Family of Distributions, Statistica, anno LXXVII, Pp. 3.

8. Cordeiro GM, Ortega EMM, Daniel CCD (2013) The exponentiated generalized class of distributions. Journal of Data Science 11(1): 1-27.

9. Clement Boateng Ampadu (2018) Quantile-Generated Family of Distributions: A New Method for Generating Continuous Distributions. Fundamental Journal of Mathematics and Mathematical Sciences, Volume 9(1): 13-34.

\section{Your next submission with Juniper Publishers} will reach you the below assets

- Quality Editorial service

- Swift Peer Review

- Reprints availability

- E-prints Service

- Manuscript Podcast for convenient understanding

- Global attainment for your research

- Manuscript accessibility in different formats

( Pdf, E-pub, Full Text, Audio)

- Unceasing customer service

Track the below URL for one-step submission https://juniperpublishers.com/online-submission.php 